\title{
Características fisiológicas de plantas hibernais com potencial fitorremediador sob influência dos herbicidas fomesafen e sulfentrazone
}

\author{
Physiological characteristics of winter cultivated plants with phytoremediation potential under the \\ influence of of the herbicides fomesafem and sulfentrazone
}
Carla Alves ${ }^{1}$, Leandro Galon ${ }^{1 \star}$, Cinthia Maethê Holz ${ }^{1}$, Rosilene Rodrigues Kaizer ${ }^{1}$, Fábio Luis Winter ${ }^{1}$, Germani Concenço ${ }^{2}$, Felipe Nonemacher ${ }^{1} \&$ Gismael Francisco Perin ${ }^{1}$

${ }^{1}$ Universidade Federal da Fronteira Sul, Erechim, RS, Brasil. ${ }^{2}$ Embrapa Clima Temperado, RS, Brasil. *Autor para correspondência: leandro.galon@uffs.edu.br.

Submissão: 22/05/2017 | Aceite: 11/06/2018

\begin{abstract}
RESUMO
O emprego de espécies vegetais para fitorremediação de solos contaminados com herbicidas persistentes, como os inibidores da enzima protoporfirinogênio oxidase (PROTOX), é uma alternativa interessante dos pontos de vista econômico e ambiental. $O$ objetivo deste trabalho foi avaliar a influência de fomesafen e sulfentrazone nas características relacionadas à fisiologia de espécies hibernais com potencial para aplicação como fitorremediadoras de solo contaminado por esses herbicidas. Dois experimentos foram instalados em casa de vegetação, um com o herbicida fomesafen e outro com 0 sulfentrazone, no delineamento de blocos casualizados com quatro repetições. Foram testadas doses dos herbicidas fomesafen $\left(0,0 ; 0,125 ; 0,250\right.$; e $\left.0,5 \mathrm{~kg} \mathrm{ha}^{-1}\right)$ e sulfentrazone $\left(0,0 ; 0,3 ; 0,6\right.$; e $\left.1,2 \mathrm{~kg} \mathrm{ha}^{-1}\right)$, marcas comerciais Flex ${ }^{\circledR}$ e Boral $500^{\circledR}$, respectivamente, aplicadas na pré-emergência das espécies com potencial fitorremediador (aveia-preta, ervilhaca, nabo e cornichão). Aos 45 dias após a emergência das plantas, foram avaliados o índice de clorofila, a eficiência de carboxilação (EC- $\mathrm{mol} \mathrm{CO}_{2} \mathrm{~m}^{-2} \mathrm{~s}^{-1}$ ), a condutância estomática de vapores de água (Gs - $\left.\mathrm{mol} \mathrm{m}^{-1} \mathrm{~s}^{-1}\right)$, a concentração interna de $\mathrm{CO}_{2}(\mathrm{Ci}-\mu \mathrm{mol}$ $\mathrm{mol}^{-1}$ ), a taxa de transpiração $\left(\mathrm{E}-\mathrm{mol} \mathrm{H}_{2} \mathrm{O} \mathrm{m}^{-2} \mathrm{~s}^{-1}\right.$ ), a quantidade de $\mathrm{CO}_{2}$ consumido (QT - $\mu \mathrm{mol} \mathrm{mol}^{-1}$ ), o uso eficiente da água (UEA - mol $\mathrm{CO}_{2} \mathrm{~mol} \mathrm{H}_{2} \mathrm{O}^{-1}$ ), a temperatura da folha $\Delta \mathrm{T}\left({ }^{\circ} \mathrm{C}\right.$ ), a taxa fotossintética ( $\mathrm{A}$ - $\left.\mu \mathrm{mol} \mathrm{m}^{-2} \mathrm{~s}^{-1}\right)$ e a massa seca $(\mathrm{g}$ vaso-1) da parte aérea. Observou-se que a ervilhaca apresenta os melhores resultados para todas as variáveis avaliadas, demonstrando assim potencial para ser testada como fitorremediadora de solos contaminados com os herbicidas fomesafen e sulfentrazone.
\end{abstract}

PALAVRAS-CHAVE: fomesafen, Lupinus albus, sulfentrazone, Vicia sativa.

\begin{abstract}
The use of plant species for phytoremediation of soil contaminated with persistent herbicides, such as inhibitors of the protoporphyrinogen oxidase enzyme (PROTOX), is an interesting alternative from the economic and environmental point of view. This work aimed to evaluate the influence of fomesafen and sulfentrazone on the characteristics related to the physiology of winter species with potential for phytoremediation of soil contaminated by these herbicides. Two experiments were installed in a greenhouse, one with the herbicide fomesafen and another with the sulfentrazone, in a randomized complete block design with four replications. Fomesafen $\left(0.0,0.125,0.250\right.$, and $\left.0.5 \mathrm{~kg} \mathrm{ha}^{-1}\right)$ and sulfentrazone $\left(0.0,0.3,0.6\right.$, and $\left.1.2 \mathrm{~kg} \mathrm{ha}^{-1}\right)$, commercial brands Flex ${ }^{\circledR}$ and Boral $500^{\circledR}$, respectively, were applied pre-emergence on species with phytoremediation potential (black oats, vetch, turnip and lotus). The chlorophyll index, the carboxylation efficiency $\left(\mathrm{EC}-\mathrm{mol} \mathrm{CO}_{2} \mathrm{~m}^{-2} \mathrm{~s}^{-1}\right)$, the stomatal conductance of water vapors (Gs - mol m$\left.{ }^{-1} \mathrm{~s}^{-1}\right)$, the internal $\mathrm{CO}_{2}$ concentration $\left(\mathrm{Ci}-\mu \mathrm{mol} \mathrm{mol}^{-1}\right)$, the transpiration rate $(\mathrm{E}$ mol $\mathrm{H}_{2} \mathrm{O} \mathrm{m}^{-2} \mathrm{~s}^{-1}$ ), the amount of $\mathrm{CO}_{2}$ consumed $\left(\mathrm{QT}-\mu \mathrm{mol} \mathrm{mol}^{-1}\right.$ ) and the water use efficiency (UEA - mol $\left.\mathrm{CO}_{2} \mathrm{~mol} \mathrm{H}_{2} \mathrm{O}_{-1}\right)$, the leaf temperature $\Delta \mathrm{T}\left({ }^{\circ} \mathrm{C}\right)$, the photosynthetic rate $\left(\mathrm{A}-\mu \mathrm{mol} \mathrm{m}^{-2} \mathrm{~s}^{-1}\right)$ and the shoot dry mass $\left(\mathrm{g} \mathrm{vase}^{-1}\right)$ were evaluated 45 days after plant emergence. It was observed that the vetch presented the best results for all evaluated variables, thus demonstrating potential to be further tested for phytoremediation of soils contaminated with the herbicides fomesafen and sulfentrazone.
\end{abstract}

KEYWORDS: fomesafen, Lupinus albus, sulfentrazone, Vicia sativa. 


\section{INTRODUÇÃO}

A permanência de alguns herbicidas no solo por longos períodos pode provocar carryover (efeito residual no solo em culturas implantadas em sucessão), apresentando maiores riscos de contaminação do ambiente, seja por lixiviação, volatilização ou erosão (INOUE et al. 2008, OLIVEIRA JR et al. 2011). Entre esses herbicidas, destaca-se o sulfentrazone e o fomesafen, inibidores da enzima protoporfirinogênio oxidase - PROTOX (DUKE et al. 1991, HESS 2000, SILVA et al. 2007). Convém ressaltar que a aplicação de herbicidas que apresentam longo período residual no solo pode resultar na impossibilidade de uso da área por espécies de interesse agrícola, suscetíveis a esses produtos (PROCÓPIO et al. 2004, SANTOS et al. 2007).

O herbicida sulfentrazone $\mathrm{N}$-[2,4-dicloro-5[4-(diflurometil)-4,5-di-hidro-3 metil-5-oxo-1H-1,2,4-triazol-1il] metanosulfonamida, pertencente ao grupo químico das triazolinonas, com meia-vida no solo ( $\mathrm{t}^{1} / 2$ ) estimada entre 110 e 280 dias, variando a partir das condições edafoclimáticas locais, sendo a atividade microbiológica seu mecanismo inicial de degradação, possui baixa dissociação em água (110 mg L-1), comportando-se como ácido fraco (pKa: 6,56); sua solubilidade aumenta com o aumento do pH (pH 6,0: 110 $\mathrm{mg} \mathrm{L}^{-1}$ e pH 7,5: $1.600 \mathrm{mg} \mathrm{L}^{-1}$ ), encontrando-se predominantemente na solução do solo na forma não ionizada (RODRIGUES \& ALMEIDA 2011). O sulfentrazone está registrado no Brasil para o controle de plantas daninhas mono e dicotiledôneas, em pré ou pós-emergência, infestantes das culturas de cana-deaçúcar, soja, citros, café, eucalipto e em áreas não agrícolas (BRASIL 2018). A absorção desse herbicida ocorre pelo sistema radicular, e sua translocação se dá por pequena movimentação pelo floema, agindo nas plantas por um processo de ruptura da membrana celular, provocando rápida dessecação foliar nas plantas que emergem (RODRIGUES \& ALMEIDA 2011).

A dissipação do sulfentrazone está diretamente relacionada com a disponibilidade de água, que pode melhorar as condições de degradação da molécula ou mesmo lixiviá-la em profundidade no solo (OHMES et al. 2000). Ao se aplicar 0,6 $\mathrm{kg} \mathrm{ha}^{-1}$ de sulfentrazone para controle de plantas daninhas infestantes da soja, a persistência do produto foi de 376 dias. Ao usarem o dobro da dose $\left(1,20 \mathrm{~kg} \mathrm{ha}^{-1}\right)$, BLANCO \& VELINI (2005) não conseguiram determinar o final da persistência do sulfentrazone, já que aos 539 dias após a aplicação ele ainda ocasionou severas injúrias sobre a cultura da beterraba - espécie utilizada como bioindicadora. Ao aplicar em cana-de-açúcar as doses de 0,6 e 1,20 kg ha-1, a persistência do sulfentrazone foi de 601 e 704 dias, respectivamente (BLANCO et al. 2010).

$\mathrm{O}$ fomesafen 5-(2-chloro- $\alpha, \alpha$, $\alpha$-trifluoro-p-tolyloxy)- $\mathrm{N}$-methyl sulfonyl-2-nitrobenzamide, pertence ao grupo químico dos difeniléteres, estando registrado no Brasil para o controle de plantas daninhas infestantes das culturas da soja e do feijão (BRASIL 2018). Apresenta solubilidade em água de $50 \mathrm{mg} \mathrm{L}^{-1}$, sendo considerado um herbicida ácido (pKa: 2,83), fortemente adsorvido pela matéria orgânica do solo. No entanto, sua sorção encontra-se estritamente relacionada com o pH do solo (GUO et al. 2003). Apesar de o fomesafen apresentar meia-vida de 66 dias, chegando a 100 dias em solos da região dos cerrados (COBUCCl et al. 1998, RAUCH et al. 2007), não se observou efeito negativo desse produto sobre a cultura do milho cultivado em sucessão à soja, 90 dias após a aplicação desse herbicida (ARTUZI \& CONTIERO 2006). Ao estudarem o comportamento de 15 genótipos de milho, RAUCH et al. (2007) encontraram diferenças nos níveis de fitotoxicidade à cultura, demonstrando haver diferenciação no comportamento entre os genótipos avaliados. DAN et al. (2011) recomendam um intervalo de segurança de 120 dias entre a aplicação do fomesafen e a semeadura do milheto para que não ocorram efeitos negativos no rendimento dessa cultura.

Considerando-se os dados de persistência relatados do sulfentrazone e do fomesafen e que o uso desses dois herbicidas ocorre em grandes áreas e culturas de interesse agrícola do Brasil, eles podem constituir-se em fonte de contaminação de águas e solos, principalmente como resultado de aplicações sequenciais ao longo dos anos. Algumas espécies têm apresentado elevada sensibilidade ao sulfentrazone, como o milheto (PEREIRA et al. 2000, DAN et al. 2011), a aveia-preta e o sorgo (PEREIRA et al. 2000), o milho cultivado em sucessão à soja (ARTUZI \& CONTIERO 2006), a canola (OLIVEIRA JR 2001) e olerícolas (SZMIGIELSKI et al. 2009), entretanto, esse herbicida não prejudicou o crescimento do girassol e do feijão (BLANCO \& VELINI 2005).

Para descontaminação de solos tratados com herbicidas, pode-se usar a técnica da fitorremediação, pela utilização de plantas isoladas ou estimulando a microbiota associada às suas raízes (SANTOS et al. 2007, CARMO et al. 2008). A fitorremediação é uma alternativa ambientalmente aceita para a despoluição de solo e água contaminados com herbicidas, e tem aumentado o número de estudos envolvendo essa técnica. Contudo, essas pesquisas são ainda incipientes e requerem muitas experimentações sob condições edafoclimáticas tropicais, para identificação de espécies capazes de atuar em programas de 
fitorremediação, à semelhança do que já é realizado em outros países do mundo, como na Europa, EUA, Nova Zelândia e Austrália (PIRES et al. 2005). Essa técnica tem trazido bons resultados na despoluição de solos brasileiros contaminados com os herbicidas tebuthiuron (PIRES et al. 2005), trifloxysulfuron-sodium (SANTOS et al. 2007), picloram (CARMO et al. 2008, SILVA et al. 2012), sulfentrazone (MADALÃO et al. 2012, BELO et al. 2016, MADALÃO et al. 2017), imazethapyr + imazapic e imazapyr + imazapic (GALON et al. 2014), ao serem utilizadas as espécies de plantas Canavalia ensiformes, Stizolobium aterrimum, Panicum maximum, Eleusine coracana, Crotalaria juncea, Helianthus annus, Canavalia ensiformis, Dolichos lablab, Arachis hypogaea e Vicia sativa, como fitorremediadoras de solo em diversas regiões do Brasil. Essas espécies, além de servirem para a despoluição de solos contaminados com herbicidas, podem ainda ser usadas como fixadores de nutrientes, pastagens para animais, produção de grãos ou cobertura vegetal, para adoção do sistema de plantio direto em diversas regiões do país.

Além dos problemas relacionados à persistência e do carryover do sulfentrazone e do fomesafen em solos, eles ainda atuam indiretamente sobre o metabolismo fotossintético das plantas em que são aplicados. Os herbicidas inibidores de PROTOX (sulfentrazone e fomesafen) afetam diversos processos fisiológicos das plantas, alterando os mecanismos de fechamento estomático, a capacidade fotossintética, a transpiração, a eficiência de carboxilação e o uso de água, parâmetros que podem indicar o efeito de herbicidas nas plantas (VARGAS et al. 2014) e também ocasionar a peroxidação de membranas celulares, entre outros efeitos (TAIZ et al. 2017).

Assim, pode-se aumentar a produtividade das culturas agrícolas ao reduzir os problemas com fitotoxicidade ocasionada por contaminação do solo com resíduos de herbicidas, em direção a uma agricultura mais sustentável (MOOSAVI \& SEGHATOLESLAMI 2013).

Objetivou-se com este trabalho avaliar a influência de fomesafen e sulfentrazone nas características relacionadas à fisiologia de espécies de inverno, como o primeiro passo para testá-las quanto ao potencial de aplicação na fitorremediação de solos contaminados com resíduos desses herbicidas.

\section{MATERIAL E MÉTODOS}

Os estudos foram conduzidos em casa de vegetação da Universidade Federal da Fronteira Sul (UFFS), Campus Erechim, entre os meses de outubro e dezembro de 2015. Foram instalados dois experimentos em delineamento de blocos casualizados com quatro repetições, sendo o primeiro com 0 herbicida fomesafen e o segundo com o sulfentrazone.

A semeadura das espécies foi feita em vasos de polietileno com capacidade para $8 \mathrm{dm}^{3}$, preenchidos com Latossolo Vermelho aluminoférrico húmico (EMBRAPA 2013), livre da aplicação de herbicidas. A correção da fertilidade do solo foi efetuada com base na sua análise química e de acordo com as recomendações técnicas para as culturas envolvidas nos ensaios (CQFS-RS/SC 2004). As características químicas e físicas do solo foram: $\mathrm{pH}$ em água de 4,8; $\mathrm{MO}=3,5 \% ; \mathrm{P}=4,0 \mathrm{mg} \mathrm{dm}^{-3} ; \mathrm{K}=117,0 \mathrm{mg} \mathrm{dm}^{-3} ; \mathrm{Al}^{3+}$ $=0,6 \mathrm{cmolc} \mathrm{dm}^{-3} ; \mathrm{Ca}^{2+}=4,7 \mathrm{cmolc} \mathrm{dm}^{-3} ; \mathrm{Mg}^{2+}=1,8 \mathrm{cmolc} \mathrm{dm}^{-3} ; \mathrm{CTC}(\mathrm{t})=7,4 \mathrm{cmolc} \mathrm{dm}^{-3} ; \mathrm{CTC}(\mathrm{TpH}=7,0)=$ $16,5 \mathrm{cmolc} \mathrm{dm}^{-3} ; \mathrm{H}+\mathrm{Al}=9,7 \mathrm{cmolc} \mathrm{dm}^{-3} ; \mathrm{SB}=6,8 \mathrm{cmolc} \mathrm{dm}^{-3} ; \mathrm{V}=41 \%$; e argila $=60 \%$.

Foram aplicadas doses de fomesafen $\left(0,0 ; 0,125 ; 0,250\right.$; e $\left.0,5 \mathrm{~kg} \mathrm{ha}^{-1}\right)$ e de sulfentrazone $(0,0 ; 0,3$; 0,6; e $1,2 \mathrm{~kg} \mathrm{ha}^{-1}$ ) sobre as espécies hibernais de aveia-preta (Avena strigosa), cornichão (Lotus corniculatus), ervilhaca (Vicia sativa) e nabo (Raphanus sativus), em pré-emergência. Os herbicidas foram aplicados utilizando-se um pulverizador costal de precisão pressurizado a $\mathrm{CO}_{2}$, equipado com duas pontas de pulverização da série TT 110.02, o qual pulverizou volume de calda de $150 \mathrm{~L} \mathrm{ha}^{-1}$.

A semeadura das espécies ocorreu um dia antes da aplicação dos herbicidas; após a germinação, efetuou-se o desbaste deixando-se dez plantas por vaso. A irrigação iniciou-se um dia antes da semeadura, sendo omitida na data da aplicação dos herbicidas, e foi controlada diariamente nas unidades experimentais, mantendo-se a umidade em torno de $80 \%$ da capacidade de campo, em vasos perfurados.

As variáveis relacionadas à fisiologia das plantas foram avaliadas aos 45 dias após a emergência. Para aferir o teor de clorofila (TC), foi utilizado um clorofilômetro portátil modelo SPAD 502 - Plus, determinando-se as medidas em cinco pontos de cada planta, nas folhas inferiores, medianas e superiores do dossel. Já a taxa fotossintética $\left(A-\mu \mathrm{mol} \mathrm{m} \mathrm{m}^{-2} \mathrm{~s}^{-1}\right)$, concentração interna de $\mathrm{CO}_{2}\left(\mathrm{Ci}-\mu \mathrm{mol} \mathrm{mol}^{-1}\right)$, quantidade de $\mathrm{CO}_{2}$ consumido (QT - $\left.\mu \mathrm{mol} \mathrm{mol}^{-1}\right)$, taxa de transpiração $\left(\mathrm{E}-\mathrm{mol} \mathrm{H}_{2} \mathrm{O} \mathrm{m} \mathrm{m}^{-2} \mathrm{~s}^{-1}\right)$, condutância estomática de vapores de água (Gs - $\mathrm{mol} \mathrm{m}^{-1} \mathrm{~s}^{-1}$ ), eficiência de carboxilação $\left(E C-\mathrm{mol} \mathrm{CO}_{2} \mathrm{~m}^{-2} \mathrm{~s}^{-1}\right.$ ), uso eficiente da água (UEA - mol $\mathrm{CO}_{2} \mathrm{~mol} \mathrm{H}_{2} \mathrm{O}^{-1}$ ) e temperatura da folha $\Delta \mathrm{T}\left({ }^{\circ} \mathrm{C}\right.$ ) foram aferidos no terço médio da primeira folha completamente expandida das plantas. A eficiência da carboxilação $\left(E C-\mathrm{mol} \mathrm{CO}_{2} \mathrm{~m}^{-2} \mathrm{~s}^{-1}\right)$ e a eficiência do uso da água (UEA - $\mathrm{mol} \mathrm{CO}_{2} \mathrm{~mol} \mathrm{H}_{2} \mathrm{O}^{-1}$ ) foram calculadas a partir da razão das variáveis $\mathrm{A} / \mathrm{Ci}$ e $\mathrm{A} / \mathrm{E}$, respectivamente. Para isso, utilizou-se um analisador de gases no infravermelho (IRGA), marca 
ADC, modelo LCA PRO (Analytical Development Co. Ltd, Hoddesdon, UK); cada bloco foi avaliado sob iluminação natural em um dia, entre oito e dez horas da manhã, em condições de céu limpo, de forma que se mantivessem as condições ambientais homogêneas durante as análises.

Após as avaliações das variáveis fisiológicas, coletou-se a parte aérea das plantas presentes em cada unidade experimental, para secagem em estufa de circulação forçada de ar a $65 \pm 5 \stackrel{\circ}{\circ}$, a fim de determinar a massa seca da parte aérea - $\mathrm{MS}\left(\mathrm{g}\right.$ vaso- $\left.{ }^{-1}\right)$.

Os dados foram submetidos à análise de variância (ANOVA) pelo teste $F$ e de regressão $(p<0,05)$; a escolha do modelo foi feita com base no fenômeno biológico, no coeficiente de determinação e na significância dos coeficientes da regressão para avaliar o efeito das doses dos herbicidas sobre as espécies estudadas. Ressalta-se que não foram efetuadas as comparações entre as espécies, por naturalmente apresentarem diferenciação. As análises estatísticas foram realizadas por meio do programa estatístico "R", e a confecção dos gráficos, pelo software Sigmaplot 12.5 .

\section{RESULTADOS E DISCUSSÃO}

Observou-se que não houve alteração no índice de clorofila (SPAD) com o aumento nas doses de fomesafen (Figura 1A) para nenhuma espécie avaliada. $O$ mesmo fenômeno ocorreu para o herbicida sulfentrazone, exceto para o cornichão, em que, ao se incrementarem as doses aplicadas, o índice de clorofila decresceu (Figura 1B).
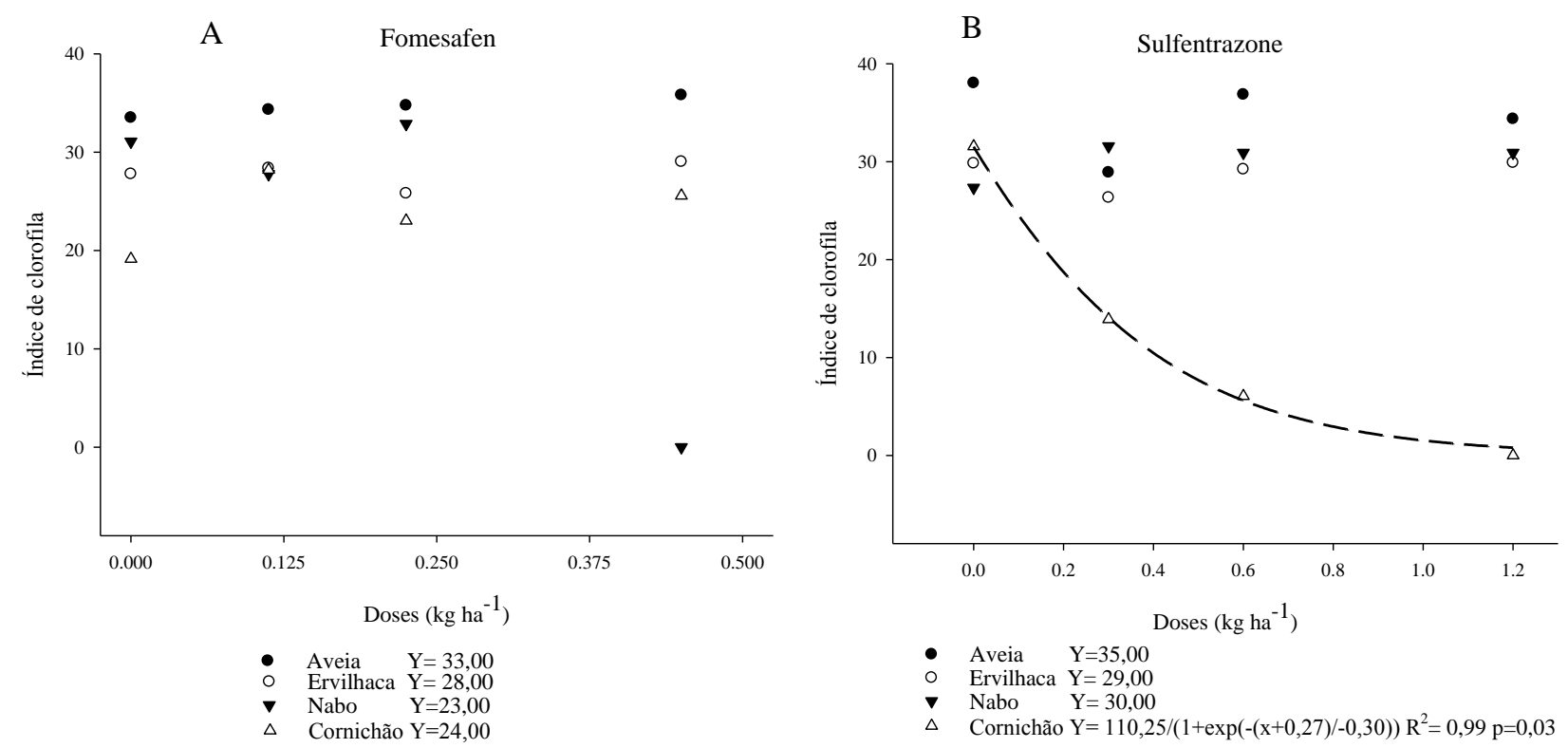

Figura 1. Índice de clorofila (SPAD) das espécies de aveia-preta (Avena strigosa), ervilhaca (Vicia sativa), nabo (Raphanus raphanistrum) e cornichão (Lotus corniculatus) aos 45 dias após a emergência, em função da aplicação de doses de fomesafen (A) e sulfentrazone (B). UFFS, Erechim, RS, 2015.

Figure 1. Chlorophyll index (SPAD) of black oat (Avena strigosa), vetch (Vicia sativa), radish (Raphanus raphanistrum) and bird's-foot trefoil (Lotus corniculatus) forty-five days after emergence, as a function of doses of fomesafen (A) and sulfentrazone (B). UFFS, Erechim, RS, Brazil, 2015.

CORRÊA \& ALVES (2010), ao avaliarem o efeito de herbicidas sobre a clorofila de plantas de soja em dois anos de cultivo, não observaram diferenças significativas ao aplicarem lactofen, glyphosate, lactofen+chlorimuron-ethyl+imazethapyr, chlorimuron-ethyl+bentazon, glyphosate+imazethapyr, lactofen+ chlorimuron-ethyl+imazethapyr e lactofen+chlorimuron-ethyl+imazethapyr/haloxyfop-methyl, comparados com os tratamentos testemunhas infestadas ou capinadas, após 18, 25 e 32 e aos 21, 28 e 35 dias após a aplicação dos herbicidas. Convém destacar que o herbicida lactofen apresenta o mesmo mecanismo de ação do fomesafen e do sulfentrazone, ou seja, inibidores de PROTOX, o que em parte corrobora os resultados encontrados no presente estudo. De forma contrária, CARRETERO (2008) observou redução nos teores de clorofila total após a aplicação de lactofen na cultura da soja, sendo os efeitos muito dependentes do estádio de aplicação e da hora de avaliação em que foi aplicado o herbicida.

Ocorreu diminuição significativa na eficiência de carboxilação $(E C)$ da aveia-preta e do nabo em função da aplicação de fomesafen em pré-emergência a partir da dose de $0,125 \mathrm{~kg} \mathrm{ha}^{-1}$, enquanto para a 
dose de $0,5 \mathrm{~kg} \mathrm{ha}^{-1}$ houve morte das plantas (Figura 2A). SILVEIRA et al. (2012) observaram que o uso de fomesafen afetou negativamente os parâmetros fotossintéticos da mandioca, causando cerca de $17 \%$ de inibição da eficiência da carboxilação, quando se comparou o uso do herbicida com a testemunha sem aplicação.
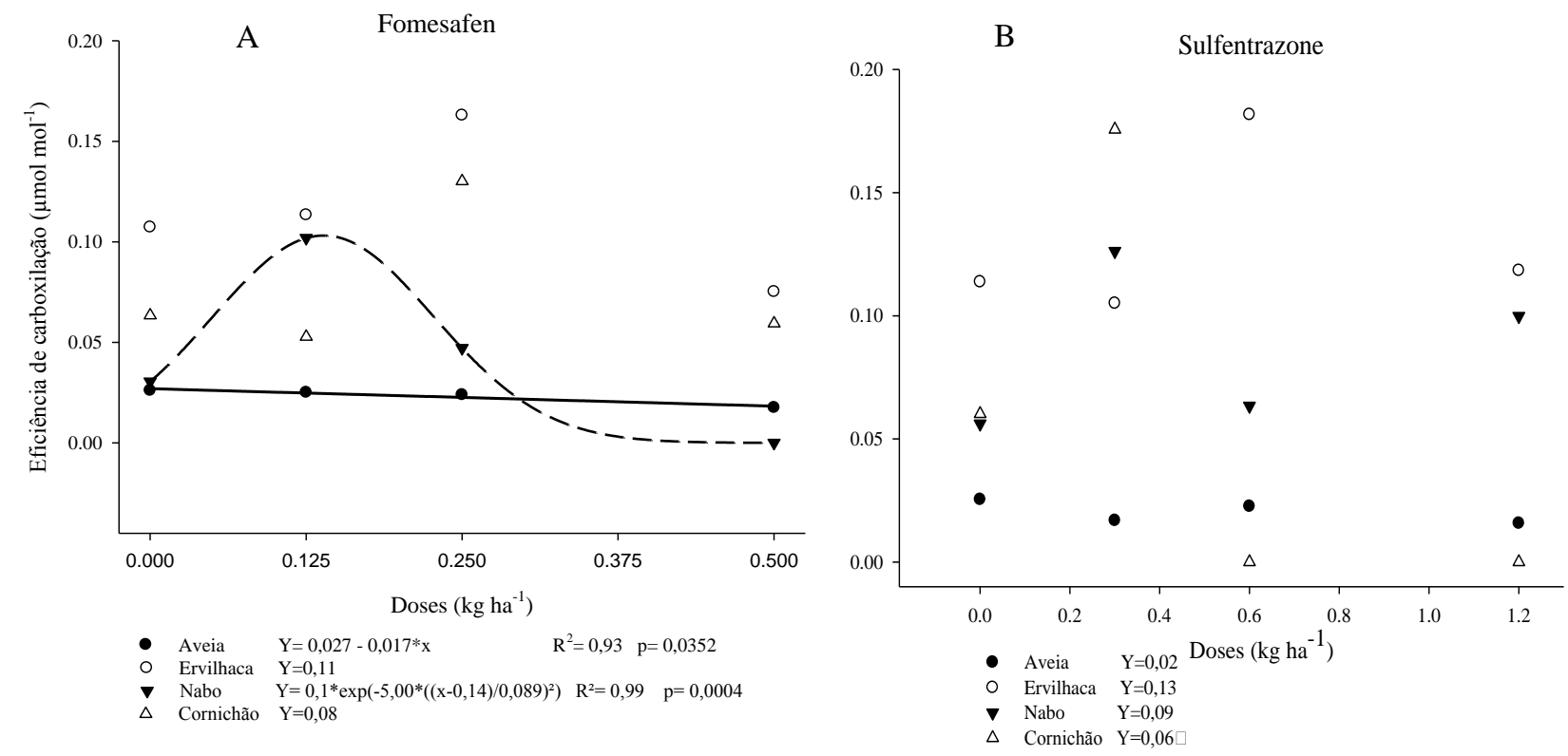

Figura 2. Eficiência de carboxilação (EC - mol $\left.\mathrm{CO}_{2} \mathrm{~m}^{-2} \mathrm{~s}^{-1}\right)$ das espécies aveia-preta (Avena strigosa), ervilhaca (Vicia sativa), nabo (Raphanus raphanistrum) e cornichão (Lotus corniculatus) aos 45 dias após a emergência, em função da aplicação de doses de fomesafen (A) e sulfentrazone (B). UFFS, Erechim, RS, 2015.

Figure 2. Carboxylation efficiency (EC - mol $\mathrm{CO}_{2} \mathrm{~m}^{-2} \mathrm{~s}^{-1}$ ) of black oat (Avena strigosa), vetch (Vicia sativa), radish (Raphanus raphanistrum) and bird's-foot trefoil (Lotus corniculatus) forty-five days after emergence, as a function of doses of fomesafen (A) and sulfentrazone (B). UFFS, Erechim, RS, Brazil, 2015.
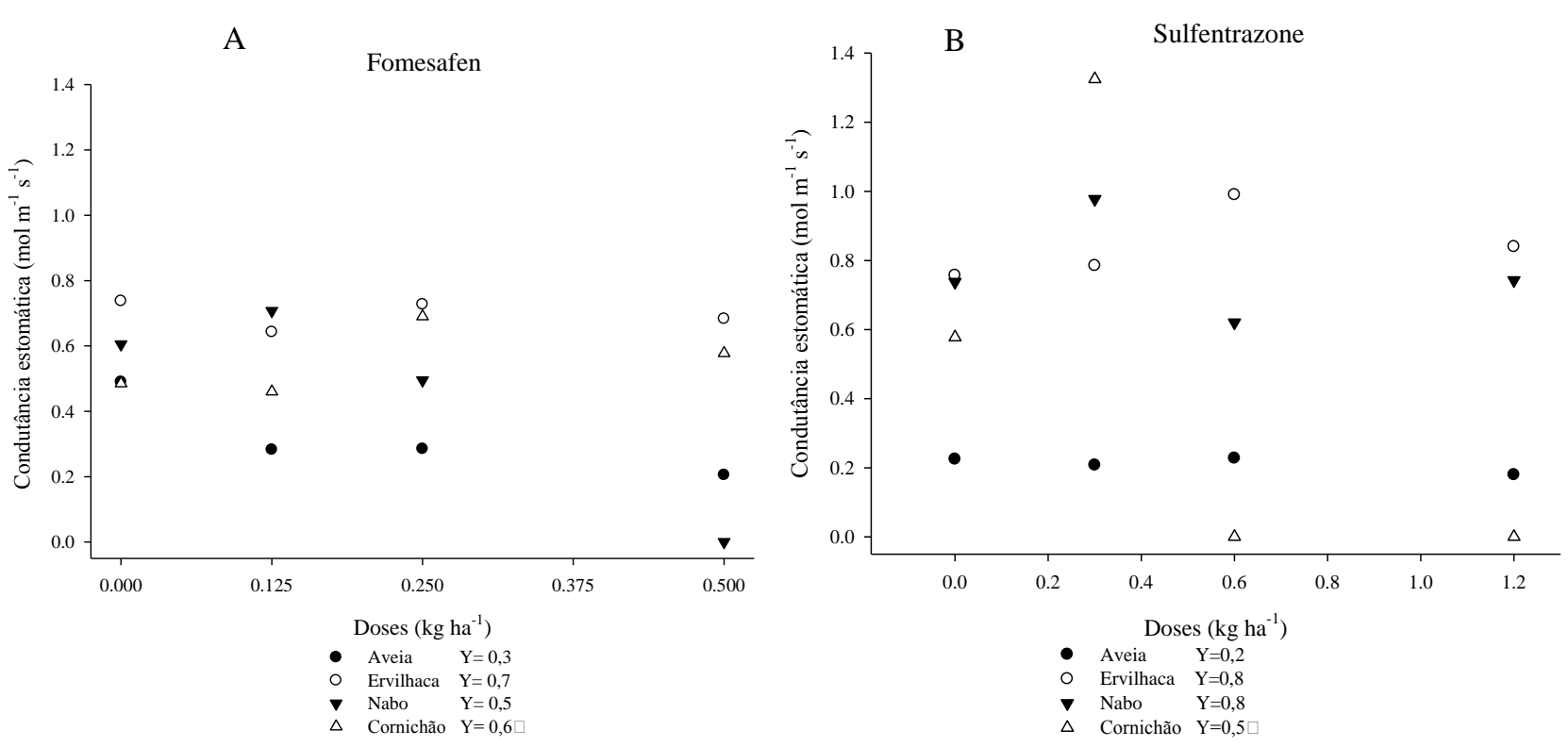

Figura 3. Condutância estomática de vapores de água $\left(G s-\mathrm{mol} \mathrm{m}^{-1} \mathrm{~s}^{-1}\right)$ das espécies aveia-preta (Avena strigosa), ervilhaca (Vicia sativa), nabo (Raphanus raphanistrum) e cornichão (Lotus corniculatus) aos 45 dias após a emergência, em função da aplicação de doses de fomesafen (A) e sulfentrazone (B). UFFS, Erechim, RS, 2015.

Figure 3. Stomatal conductance of water vapors (Gs - mol $\mathrm{m}^{-1} \mathrm{~s}^{-1}$ ) from black oat (Avena strigosa), vetch (Vicia sativa), radish (Raphanus raphanistrum) and bird's-foot trefoil (Lotus corniculatus) forty-five days after emergence, as a function of doses of fomesafen (A) and sulfentrazone (B). UFFS, Erechim, RS, Brazil, 2015. 
As espécies submetidas ao sulfentrazone não demonstraram diferenças significativas na EC com o incremento das doses do herbicida (Figura 2B). BELO et al. (2016), ao avaliarem o efeito das doses de 250 e $500 \mathrm{~g} \mathrm{ha}^{-1}$, também não observaram alteração média da EC de Canavalia ensiformis ao se comparar com a testemunha sem aplicação do herbicida, o que corrobora os resultados do presente estudo.

A condutância estomática de vapores de água (Gs) não foi influenciada negativamente pelos herbicidas em todas as espécies avaliadas (Figura 3), comportamento esse semelhante ao da eficiência de carboxilação (EC) e da taxa de transpiração (E) (Figura 4). A condutância foliar é composta em pequena parte pela condutância cuticular da epiderme e, quando os estômatos estão abertos, pela Gs, logo, as células-guarda dos estômatos é que passam a controlar o processo. Desse modo, a Gs é proporcional ao número e tamanho dos estômatos e diâmetro da abertura destes - características estas que dependem de fatores endógenos e ambientais de cada espécie avaliada (BRODRIBB \& HOLBROOK 2003). REIS et al. (2014), ao avaliarem o efeito dos herbicidas oxadiazon, flumioxazin, oxyfluorfen e sulfentrazone, pertencentes aos inibidores de PROTOX, aplicados na pré-emergência do girassol, não observaram alterações na condutância estomática (GS) e na taxa transpiratória (E) das plantas. A taxa de transpiração de Helianthus annus e Arachis hypogaea não mostrou alteração ao ser submetida à aplicação de 250 e 500 $\mathrm{g}$ ha $^{-1}$ de sulfentrazone no solo (BELO et al. 2016), o que se assemelha aos resultados encontrados neste estudo.
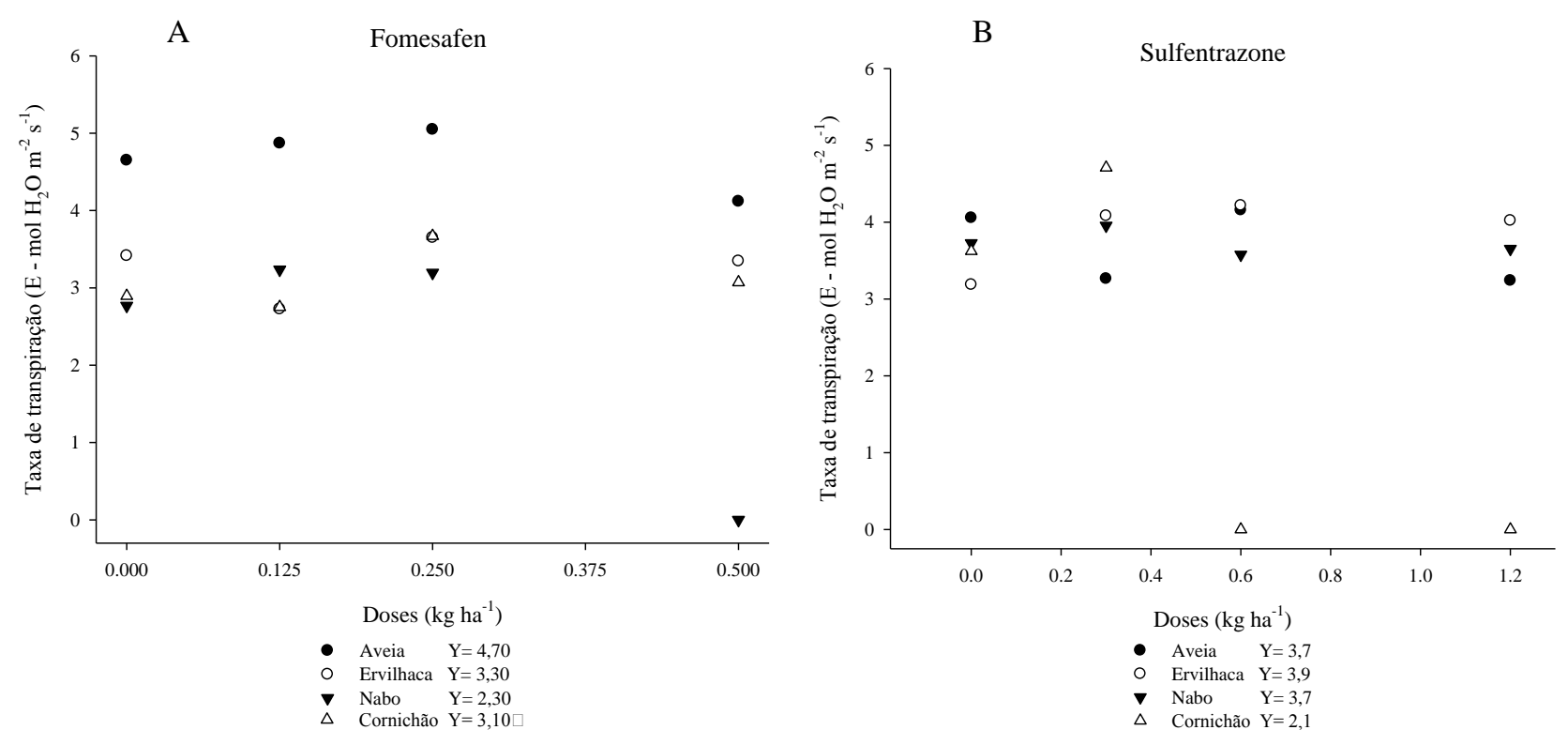

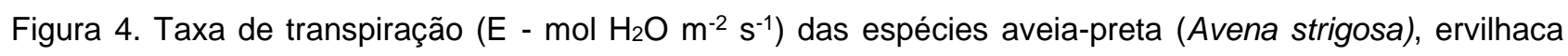
(Vicia sativa), nabo (Raphanus raphanistrum) e cornichão (Lotus corniculatus) aos 45 dias após a emergência, em função da aplicação de doses de fomesafen (A) e sulfentrazone (B). UFFS, Erechim, RS, 2015.

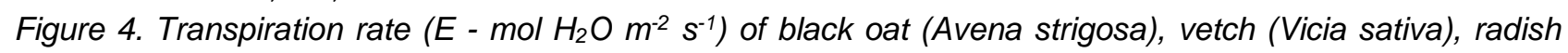
(Raphanus raphanistrum) and bird's-foot trefoil (Lotus corniculatus) forty-five days after emergence, as a function of doses of fomesafen (A) and sulfentrazone (B). UFFS, Erechim, RS, Brazil, 2015.

As espécies avaliadas não apresentaram efeito na concentração interna de $\mathrm{CO}_{2}$ em relação à aplicação de todas as doses dos herbicidas fomesafen e sulfentrazone (Figura 5). Corroborando os resultados do presente estudo, REIS et al. (2014), ao usarem o oxadiazon, flumioxazin, oxyfluorfen e sulfentrazone, também não observaram efeito desses herbicidas sobre a relação entre as concentrações interna e externa de $\mathrm{CO}_{2}$ e o consumo de $\mathrm{CO}_{2}$ das plantas de girassol, aos 27 dias após a aplicação dos produtos.

Para os resultados da quantidade de $\mathrm{CO}_{2}$ consumido, as plantas de aveia-preta apresentaram diminuição linear ao se aplicar o fomesafen (Figura 6A), assim como evidenciado na eficiência de carboxilação (Figura 2A). As plantas submetidas ao sulfentrazone não mostraram diferenças significativas em relação à testemunha, mesmo com a aplicação da maior dose do herbicida (Figura 6B). Resultados similares foram observados em girassol, feijão-de-porco e amendoim, ocorrendo redução no gradiente de 
$\mathrm{CO}_{2}$, cultivados em solo tratado com sulfentrazone, em comparação ao tratamento sem herbicida, com diminuição dos valores conforme o aumento da concentração de sulfentrazone no solo. Já para a espécie Dolichos lablab não ocorreu redução no gradiente de $\mathrm{CO}_{2}$ com o uso de sulfentrazone (BELO et al. 2016).
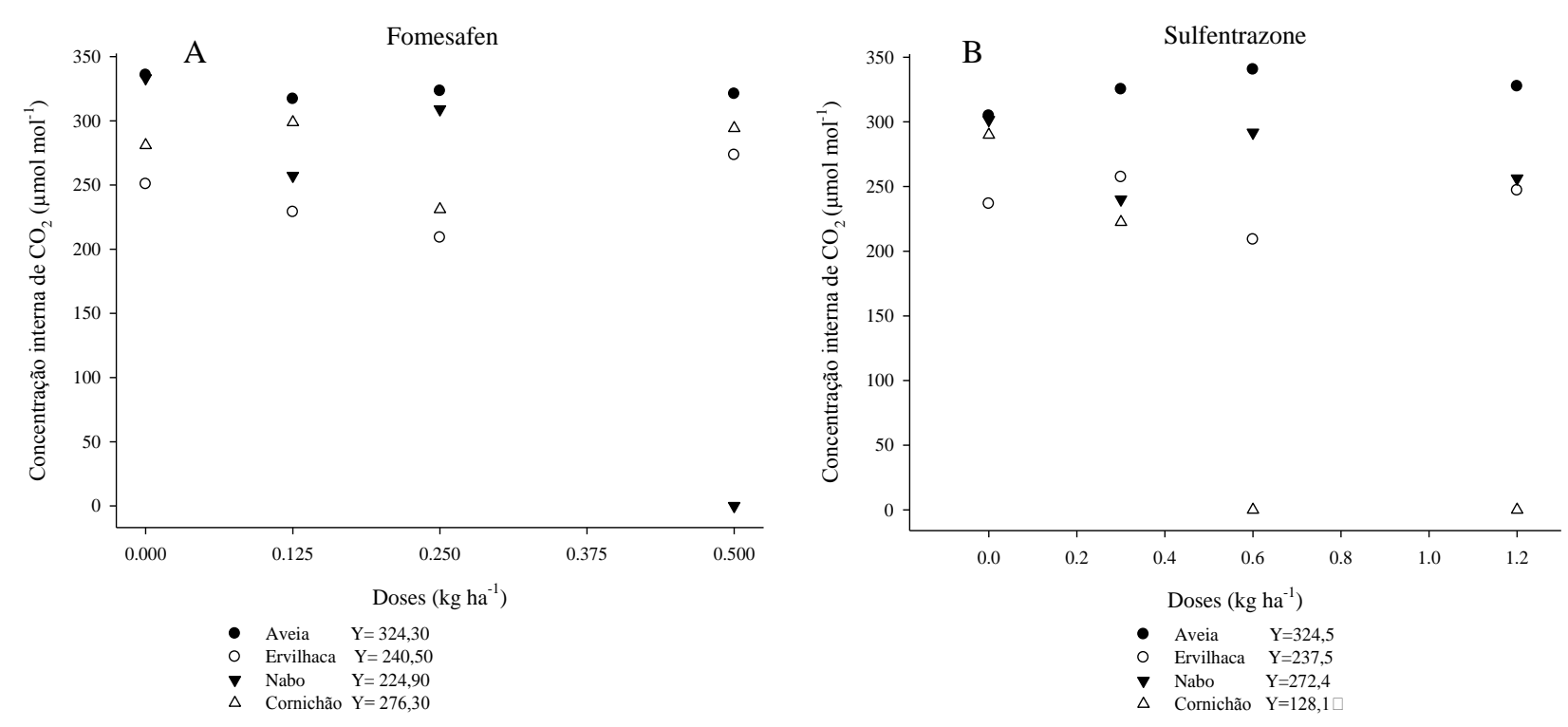

Figura 5. Concentração interna de $\mathrm{CO}_{2}\left(\mathrm{Ci}-\mu \mathrm{mol} \mathrm{mol}^{-1}\right)$ das espécies aveia-preta (Avena strigosa), ervilhaca (Vicia sativa), nabo (Raphanus raphanistrum) e cornichão (Lotus corniculatus) aos 45 dias após a emergência, em função da aplicação de doses de fomesafen (A) e sulfentrazone (B). UFFS, Erechim, RS, 2015.

Figure 5. Internal concentration of $\mathrm{CO}_{2}\left(\mathrm{Ci}-\mu \mathrm{mol} \mathrm{mol}^{-1}\right)$ in leaves of black oat (Avena strigosa), vetch (Vicia sativa), radish (Raphanus raphanistrum) and bird's-foot trefoil (Lotus corniculatus) forty-five days after emergence, as a function of doses of fomesafen $(A)$ and sulfentrazone (B). UFFS, Erechim, RS, Brazil, 2015.
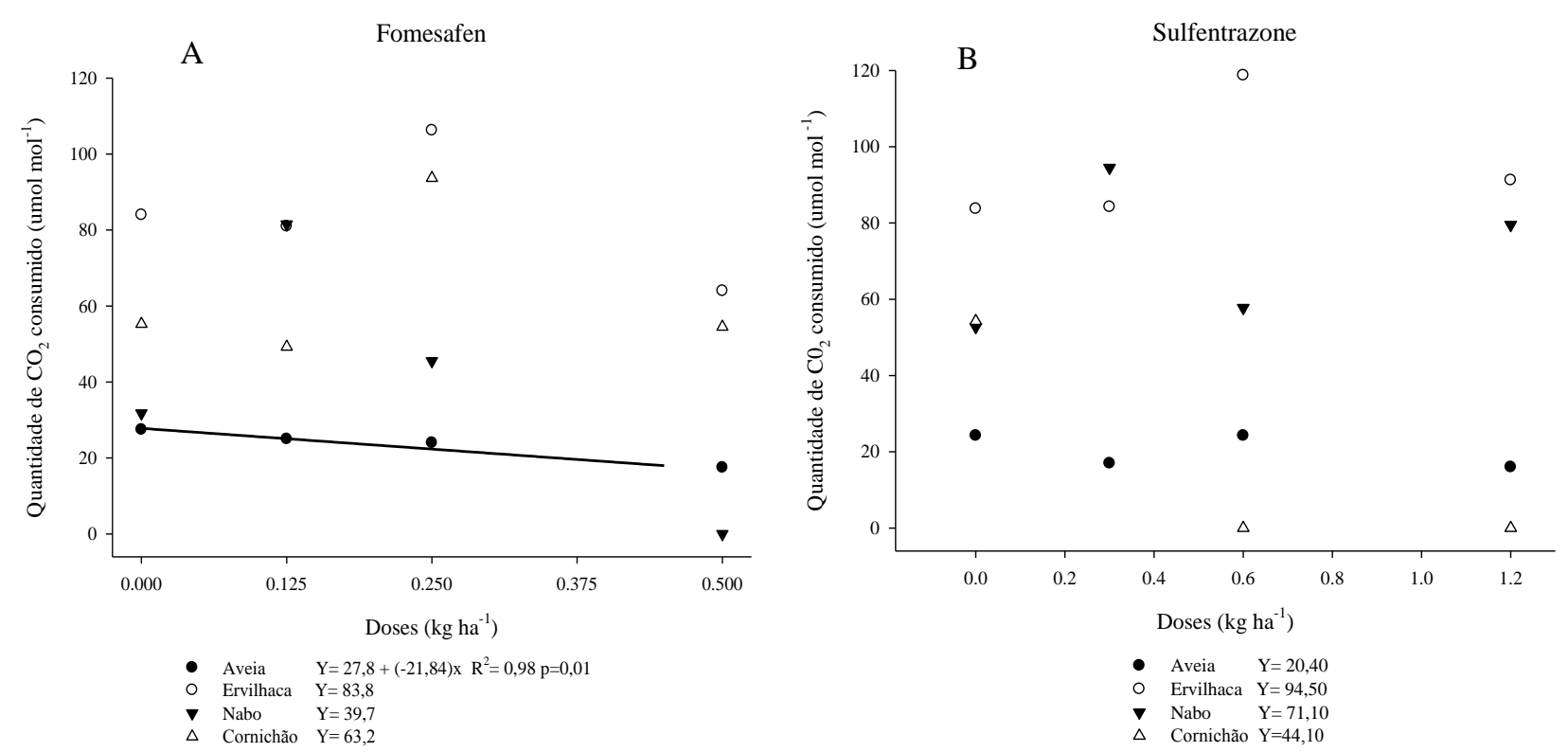

Figura 6. Quantidade de $\mathrm{CO}_{2}$ consumido (QT - $\mu \mathrm{mol} \mathrm{mol}^{-1}$ ) das espécies aveia-preta (Avena strigosa), ervilhaca (Vicia sativa), nabo (Raphanus raphanistrum) e cornichão (Lotus corniculatus) aos 45 dias após a emergência, em função da aplicação de doses de fomesafen (A) e sulfentrazone (B). UFFS, Erechim, RS, 2015.

Figure 6. Amount of $\mathrm{CO}_{2}$ consumed ( $Q T-\mu \mathrm{mol} \mathrm{mol}^{-1}$ ) by black oat (Avena strigosa), vetch (Vicia sativa), radish (Raphanus raphanistrum) and bird's-foot trefoil (Lotus corniculatus) forty-five days after emergence, as a function of doses of fomesafen $(A)$ and sulfentrazone (B). UFFS, Erechim, RS, Brazil, 2015. 
A aplicação de doses de fomesafen e sulfentrazone não demonstrou diferenças significativas na eficiência do uso da água em todas as espécies testadas e doses aplicadas (Figura 7). REIS et al. (2014), ao avaliarem o efeito dos herbicidas oxadiazon, flumioxazin, oxyfluorfen e sulfentrazone aplicados na préemergência da cultura do girassol, e TORRES et al. (2012), ao usarem vários herbicidas, entre os quais o sulfentrazone, sobre cultivares de cana-de-açúcar, também não observaram diferenças significativas no uso eficiente da água, o que vem ao encontro dos resultados encontrados no presente estudo. Caracteriza-se como eficiência do uso da água a quantidade de água transpirada por uma cultura para a produção de determinada quantidade de massa seca (SILVA et al. 2007). Desse modo, as culturas mais eficientes no uso da água podem produzir quantidade maior de massa seca por grama de água transpirada. O uso mais eficiente da água está diretamente relacionado ao tempo de abertura estomática, pois, enquanto a planta absorve $\mathrm{CO}_{2}$ para a fotossíntese, a água é perdida por transpiração, com intensidade variável, dependendo do gradiente de potencial entre a superfície foliar e a atmosfera, seguindo uma corrente de potenciais hídricos (CONCENÇO et al. 2007).
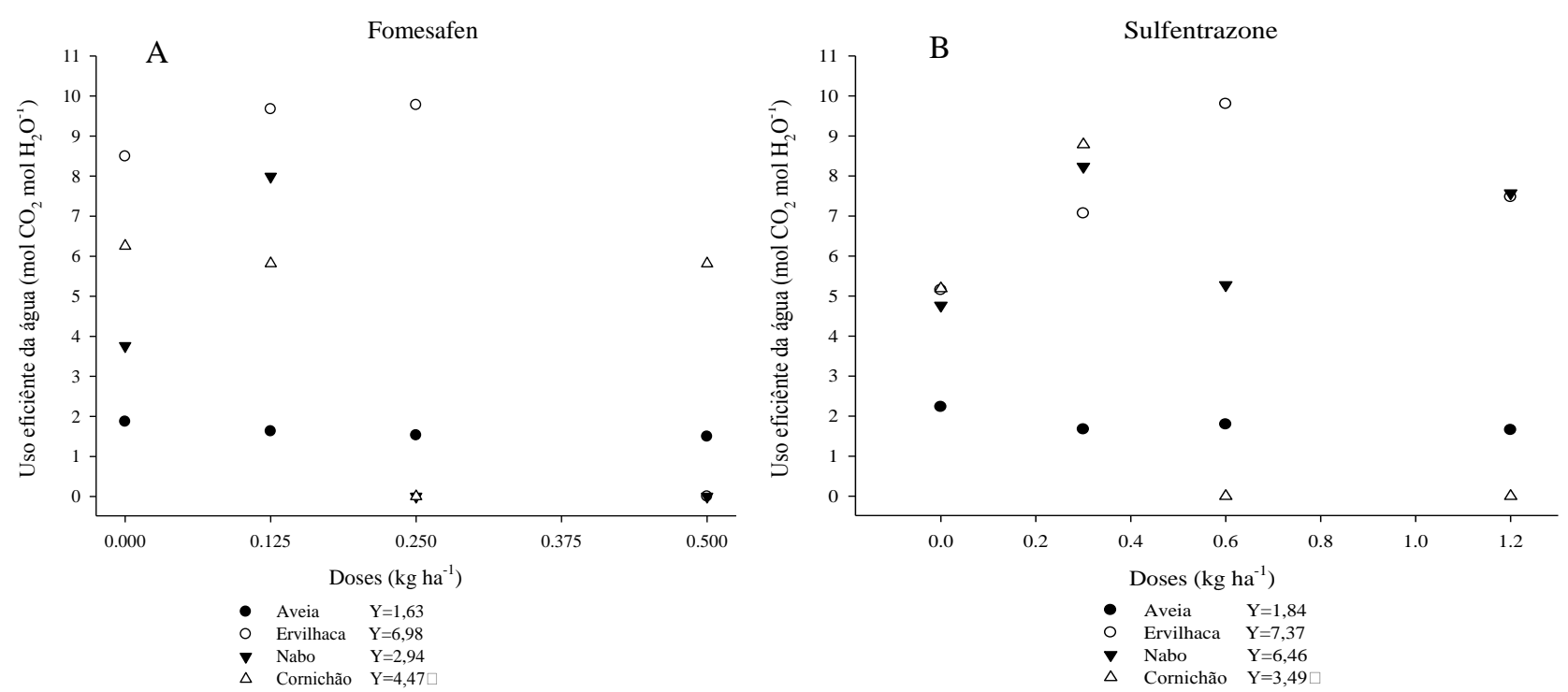

Figura 7. Uso eficiente da água (EUA- $\mathrm{mol} \mathrm{CO}_{2} \mathrm{~mol} \mathrm{H}_{2} \mathrm{O}^{-1}$ ) das espécies aveia-preta (Avena strigosa), ervilhaca (Vicia sativa), nabo (Raphanus raphanistrum) e cornichão (Lotus corniculatus) aos 45 dias após a emergência, em função da aplicação de doses de fomesafen (A) e sulfentrazone (B). UFFS, Erechim, RS, 2015.

Figure 7. Water use efficiency (EUA - $\mathrm{mol} \mathrm{CO}_{2} \mathrm{~mol} \mathrm{H}_{2} \mathrm{O}^{-1}$ ) of black oat (Avena strigosa), vetch (Vicia sativa), radish (Raphanus raphanistrum) and bird's-foot trefoil (Lotus corniculatus) forty-five days after emergence, as a function of doses of fomesafen $(A)$ and sulfentrazone (B). UFFS, Erechim, RS, Brazil, 2015.

As espécies testadas não diferiram significativamente da testemunha no que se refere ao gradiente de temperatura da folha e do ambiente, para os dois herbicidas testados, ocorrendo variações de cerca de $1 \stackrel{\circ}{\circ}$ (Figura 8). GALON et al. (2010), ao avaliarem diferentes genótipos de cana-de-açúcar submetidos à aplicação de herbicidas, não observaram diferenças significativas entre os tratamentos, e as variações no gradiente térmico foram em torno de $2,5^{\circ} \mathrm{C}$. O gradiente térmico $(\Delta \mathrm{T})$ pode estar relacionado à intensidade metabólica do vegetal, expressando a quantos graus a temperatura da folha se encontrava acima da temperatura ambiente no momento da avaliação (CONCENÇO et al. 2007, CONCENÇO et al. 2009).

A diminuição na taxa de transpiração está associada ao fechamento dos estômatos, e as variações na abertura destes causa alterações no potencial hídrico (BRODRIBB \& HILL 2000). A diminuição dos níveis de luminosidade ocasiona o fechamento dos estômatos, pois a luz está abaixo da radiação fotossinteticamente ativa ou para evitar o estresse hídrico (COCHARD et al. 2002). Todas as variáveis estão diretamente relacionadas, como, por exemplo, o fato de o gradiente de temperatura da folha e do ambiente ser alterado pela E. A Gs é ativa quando os estômatos estão abertos para a captura de $\mathrm{CO}_{2}$ e para a transpiração (GALON et al. 2010).

A taxa fotossintética da aveia-preta sofreu diminuição com o aumento das doses de fomesafen (Figura 9A). Observou-se que a aplicação de $500 \mathrm{~g}$ de fomesafen em pré-emergência reduziu a taxa fotossintética da aveia-preta em aproximadamente $35 \%$, em comparação com a testemunha sem aplicação 
de herbicida $\left(0 \mathrm{~g} \mathrm{ha}^{-1}\right)$. As plantas de ervilhaca e cornichão não apresentaram ajuste dos dados a nenhum dos modelos testados, com taxas fotossintéticas médias de 26,88 e $20,28 \mathrm{umol} \mathrm{m}^{-2} \mathrm{~s}^{-1}$, respectivamente. $\mathrm{O}$ nabo apresentou aumento significativo na taxa fotossintética ao se aplicar $0,125 \mathrm{~kg} \mathrm{ha}^{-1}$ de fomesafen. Ocorreu redução significativa da taxa com o aumento das doses $\left(0,25\right.$ e $\left.0,35 \mathrm{~kg} \mathrm{ha}^{-1}\right)$, havendo redução no uso de $0,25 \mathrm{~kg} \mathrm{ha}^{-1}$ e morte das plantas com o uso da maior dose (Figura 9A). Isso indica que, em subdoses de fomesafen, essa espécie é capaz de promover alterações no seu metabolismo primário, de forma a reduzir o impacto do herbicida sobre a fotossíntese.
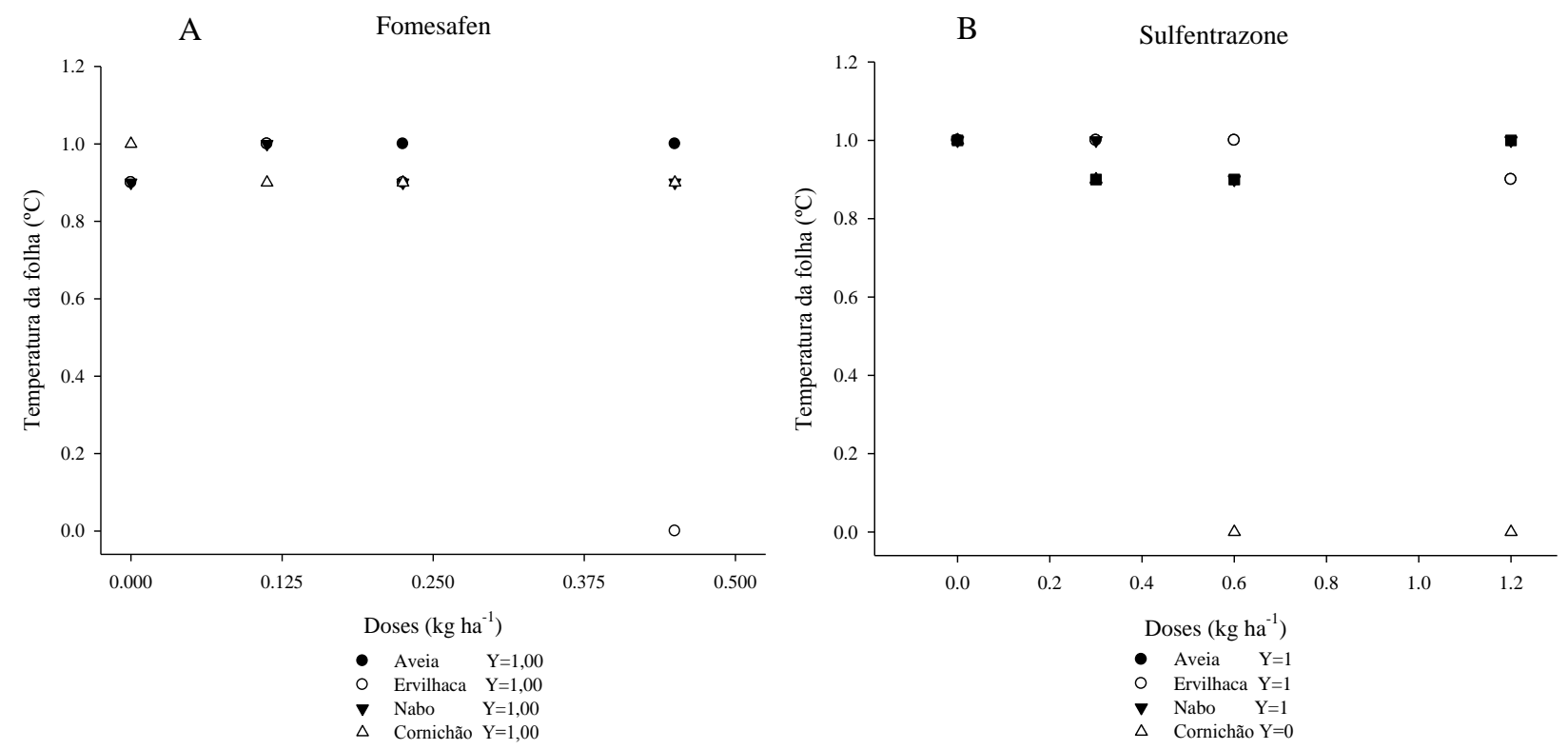

Figura 8. Variação da temperatura da folha em relação ao ambiente $\left(\Delta T-{ }^{\circ} C\right)$ das espécies aveia-preta (Avena strigosa), ervilhaca (Vicia sativa), nabo (Raphanus raphanistrum) e cornichão (Lotus corniculatus) aos 45 dias após a emergência, em função da aplicação de doses de fomesafen (A) e sulfentrazone (B). UFFS, Erechim, RS, 2015.

Figure 8. Thermal gradient between leaf and the surrounding air $\left(\Delta T-{ }^{\circ} C\right)$ of black oat (Avena strigosa), vetch (Vicia sativa), radish (Raphanus raphanistrum) and bird's-foot trefoil (Lotus corniculatus) forty-five days after emergence, as a function of doses of fomesafen (A) and sulfentrazone (B). UFFS, Erechim, RS, Brazil, 2015.

CARRETERO (2008) relatou, ao aplicar lactofen em soja, que ocorreu redução da taxa fotossintética das plantas tratadas com esse herbicida. Já as plantas tratadas com o sulfentrazone não apresentaram ajustes aos modelos avaliados para nenhuma das doses aplicadas, tendo-se valores de taxa fotossintética de 6,52; 30,30; 22,83 e 14,13 $\mu \mathrm{mol} \mathrm{m} \mathrm{m}^{-2} \mathrm{~s}^{-1}$, respectivamente para aveia-preta, ervilha, nabo e cornichão (Figura 9B). REIS et al. (2014) também não constataram diferenças significativas ao testarem o efeito dos herbicidas sulfentrazone, oxyfluorfen, flumioxazin e oxadiazon (inibidores de PROTOX) sobre a taxa fotossintética das cultivares de mandioca Cacau-UFV, Platina, Coqueiro, Coimbra e IAC-12, com valores dessa variável de 23,76; 25,47; 21,67; e 24,35 $\mu \mathrm{mol} \mathrm{m}^{-2} \mathrm{~s}^{-1}$, respectivamente.

A diminuição da taxa fotossintética pode estar relacionada com as trocas gasosas, e a diminuição da clorofila (BELO et al. 2011), com o mecanismo de ação dos herbicidas que foram utilizados no presente estudo; assim, os resultados observados são consequência direta do mecanismo de ação do fomesafen e do sulfentrazone, ambos inibidores de PROTOX.

A taxa fotossintética da cultivar de cana-de-açúcar RB 855156 foi reduzida cerca de $35 \%$ ao se comparar a aplicação de 1,2 $\mathrm{L}$ ha-1 de sulfentrazone com a testemunha sem herbicida (TORRES et al. 2012). De modo similar ao presente estudo, BELO et al. (2016) observaram redução da taxa fotossintética de plantas de Helianthus annuus, Dolichos lablab e Arachis hypogaea quando cultivadas em solo contaminado com sulfentrazone, com elevada redução nas maiores concentrações do herbicida. Esses mesmos autores relatam que a taxa fotossintética de Dolichos lablab e Arachis hypogaea reduziu aproximadamente $21 \%$ e $34 \%$, respectivamente, ao se comparar a dose de $500 \mathrm{~g} \mathrm{ha}^{-1}$ do sulfentrazone coma testemunha sem herbicida.

A aveia-preta, a ervilhaca, o nabo e o cornichão não apresentaram ajustes aos modelos testados para a massa seca da parte aérea quando se aplicou o fomesafen (Figura 10A). A aveia-preta apresentou 
redução de cerca de $44 \%$ no acúmulo de MS ao se comparar o uso de $1,2 \mathrm{~kg} \mathrm{ha}^{-1}$ contra a testemunha sem aplicação de sulfentrazone (Figura 10B). A ervilhaca, o nabo e o cornichão não se ajustaram aos modelos testados, apresentando acúmulos de MS de 1,26, 3,51 e 0,18 g, respectivamente.
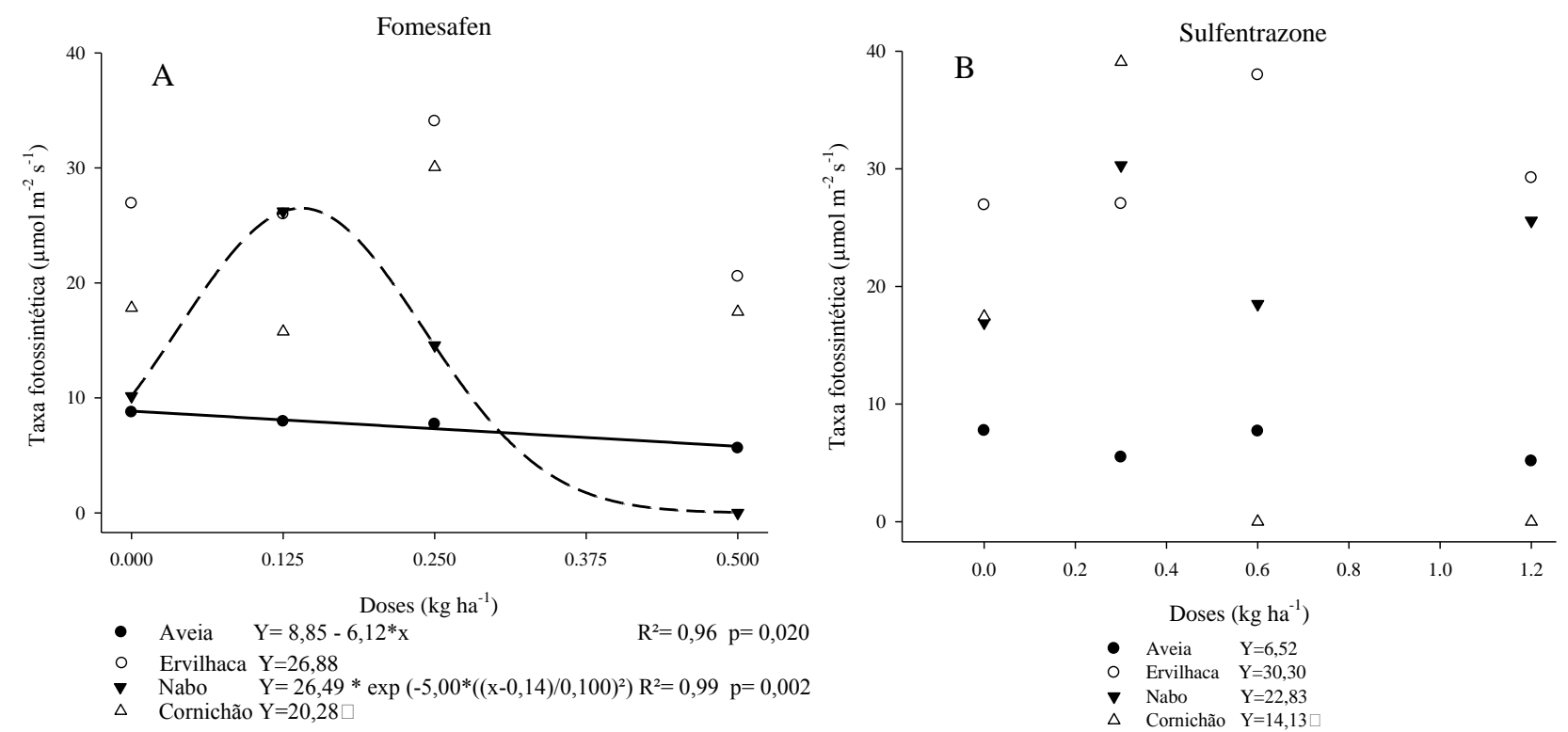

Figura 9. Taxa fotossintética (A - $\mu \mathrm{mol} \mathrm{m}^{-2} \mathrm{~s}^{-1}$ ) das espécies aveia-preta (Avena strigosa), ervilhaca (Vicia sativa), nabo (Raphanus raphanistrum) e cornichão (Lotus corniculatus) aos 45 dias após a emergência, em função da aplicação de doses de fomesafen (A) e sulfentrazone (B). UFFS, Erechim, RS, 2015.

Figure 9. Photosynthesis rate $\left(A-\mu \mathrm{mol} \mathrm{m} \mathrm{m}^{-2} \mathrm{~s}^{-1}\right)$ of black oat (Avena strigosa), vetch (Vicia sativa), radish (Raphanus raphanistrum) and bird's-foot trefoil (Lotus corniculatus) forty-five days after emergence, as a function of doses of fomesafen (A) and sulfentrazone (B). UFFS, Erechim, RS, Brazil, 2015.
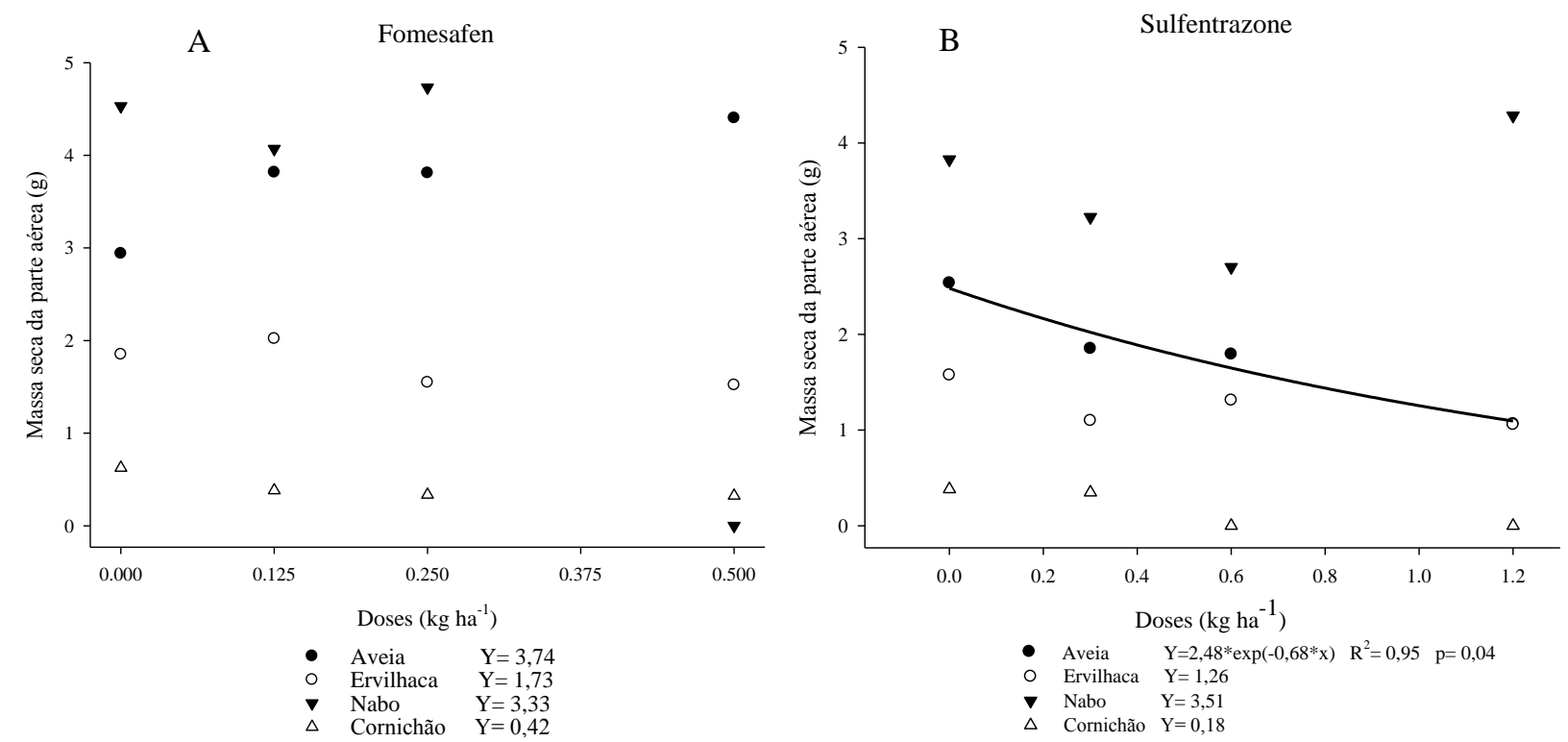

Figura 10. Massa seca da parte aérea $\left(\mathrm{g} \mathrm{vaso}^{-1}\right.$ ) das espécies aveia-preta (Avena strigosa), ervilhaca (Vicia sativa), nabo (Raphanus raphanistrum) e cornichão (Lotus corniculatus) aos 45 dias após a emergência, em função da aplicação de doses de fomesafen (A) e sulfentrazone (B). UFFS, Erechim, RS, 2015.

Figure 10. Dry mass of the aerial part ( $g$ vase $^{-1}$ ) of black oat (Avena strigosa), vetch (Vicia sativa), radish (Raphanus raphanistrum) and bird's-foot trefoil (Lotus corniculatus) forty-five days after emergence, as a function of doses of fomesafen (A) and sulfentrazone (B). UFFS, Erechim, RS, Brazil, 2015. 
REIS et al. (2014), ao avaliarem a massa seca foliar do girassol, observaram que as planta tratadas com flumioxazin, sulfentrazone e oxyfluorfen não diferiram da testemunha sem aplicação de herbicida. $O$ acúmulo de massa seca da parte aérea das plantas de Helianthus annuus, Canavalia ensiformis, Dolichos lablab e Arachis hypogaea não foi influenciado pela ação do sulfentrazone, independentemente das doses aplicadas no estudo de BELO et al. (2016), comprovando a tolerância dessas espécies ao herbicida, que é uma das características altamente desejáveis para que uma espécie seja usada como fitorremediadora. Os resultados relatados por REIS et al. (2014) e BELO et al. (2016) ao aplicarem herbicidas inibidores de PROTOX assemelham-se aos encontrados no presente estudo, com algumas espécies tolerando mais e outras menos esses produtos.

Foi possível observar que as espécies avaliadas sofreram alterações nas variáveis relacionadas às características fisiológicas e que os efeitos estão relacionados com o herbicida aplicado e as doses dele. De forma similar, BELO et al. (2016), ao estudarem o efeito da aplicação de diferentes doses de sulfentrazone sobre as espécies Helianthus annuus, Canavalia ensiformis, Dolichos lablab e Arachis hypogaea, também observaram alterações de variáveis relacionadas à fisiologia das plantas na presença do herbicida; a intensidade desse efeito variou com a espécie vegetal e com a dose aplicada.

\section{CONCLUSÃO}

Ocorreu reduzido efeito do aumento das doses de fomesafen e de sulfentrazone sobre a fisiologia das plantas de ervilhaca; desse modo, essa espécie apresenta a possibilidade de ser usada como fitorremediadora de solos tratados com os herbicidas.

A quantidade de $\mathrm{CO}_{2}$ consumida de aveia-preta foi afetada negativamente pelo aumento das doses de fomesafen.

O aumento das doses de fomesafen afetou negativamente a eficiência de carboxilação e a taxa fotossintética da aveia-preta e do nabo.

$O$ incremento das doses de sulfentrazone reduziu significativamente 0 índice de clorofila do cornichão.

A massa seca da parte aérea da aveia-preta foi afetada negativamente pelo incremento das doses de sulfentrazone.

\section{AGRADECIMENTOS}

Ao CNPq, à FAPERGS e ao FINEp, pela concessão de auxílio financeiro à pesquisa e pelas bolsas concedidas.

\section{REFERÊNCIAS}

ARTUZI JP \& CONTIERO RL 2006. Herbicidas aplicados na soja e produtividade do milho em sucessão. Pesquisa Agropecuária Brasileira 41:1119-1123.

BELO AF et al. 2011. Atividade fotossintética de plantas cultivadas em solo contaminado com picloram. Planta Daninha 29: 885-892.

BELO AF et al. 2016. Atividade fotossintética de plantas cultivadas em solo contaminado com sulfentrazone. Revista Brasileira de Herbicidas 15: 165-174.

BRASIL. 2018. Ministério da Agricultura e Pecuária. Agrofit. Disponível em: www.agricultura.gov.br. Acesso em: 20 mai. 2018.

BLANCO FMG \& VELINI ED 2005. Persistência do herbicida sulfentrazone em solo cultivado com soja e seu efeito em culturas sucedâneas. Planta Daninha 23:693-700.

BLANCO FMG et al. 2010. Persistência do herbicida sulfentrazone em solo cultivado com cana-de-açúcar. Bragantia 69: 71-75.

BRODRIBB TJ \& HILL RS 2000. Increases in water potential gradient reduce xylem conductivity in whole plants. Evidence from a low-pressure conductivity method. Plant Physiology 123: 1021-1028.

BRODRIBB TJ \& HOLBROOK NM 2003. Stomatal closure during leaf dehydration, correlation with other leaf physiological traits. Plant Physiology 132: 2166-2173.

CARMO ML et al. 2008. Influência do período de cultivo de Panicum maximum (cultivar Tanzânia) na fitorremediação de solo contaminado com picloram. Planta Daninha 26: 315-322.

CARRETERO DM. 2008. Efeito da inibição da protoporfirinogênio IX oxidase sobre trocas gasosas e fluorescência da clorofila a em plantas de soja (Glycine max L. Merrill). Dissertação (Mestrado em Fisiologia Vegetal). Viçosa: UFV. $57 \mathrm{p}$.

CQFS-RS/SC. 2004. Comissão de Química e Fertilidade do Solo. Manual de adubação e calagem para os estados do Rio Grande do Sul e de Santa Catarina. 10.ed. Porto Alegre. 400p.

COBUCCI T et al. 1998. Effect of imazamox, fomesafen and acifluorfen soil residue on rotational crops. Weed Science 
46:258-263.

COCHARD H et al. 2002. Unraveling the effects of plant hydraulics on stomatal closure during water stress in walnut. Plant Physiology 128:282-290.

CONCENÇO G et al. 2007. Uso da água em biótipos de azevém (Lolium multiflorum) em condição de competição. Planta Daninha 25:449-455.

CONCENÇO G et al. 2009. Uso da água por plantas de arroz em competição com biótipos de Echinochloa crusgalli resistente e suscetível ao herbicida quinclorac. Planta Daninha 27: 249-256.

CORRÊA MJP \& ALVES PLCA 2010. Efeitos da aplicação de herbicidas sobre a eficiência fotoquímica em plantas de soja convencional e geneticamente modificada. Ciência e Agrotecnologia 34: 1136-1145.

DAN HA et al. 2011. Atividade residual de herbicidas aplicados em pós-emergência na cultura da soja sobre o milheto cultivado em sucessão. Planta Daninha 29: 663-671.

DUKE SO et al. 1991. Protoporphyrinogen oxidase-inhibiting herbicides. Weed Science 39: 465-473.

EMBRAPA. 2013. Empresa Brasileira de Pesquisa Agropecuária. Sistema brasileiro de classificação de solos. Brasília: Embrapa Solos. 154p.

GALON L et al. 2010. Eficiência de uso da água em genótipos de cana-de-açúcar submetidos à aplicação de herbicidas. Planta Daninha 28: 777-784.

GALON L et al. 2014. Influência de herbicidas do grupo das imidazolinas em características fisiológicas de plantas cultivadas no inverno. Pesquisa Agropecuária Gaúcha 20: 42-51.

GUO J et al. 2003. Adsorption, desorption and mobility of fomesafen in Chinese soils. Water, Air, and Soil Pollution 148: 77-85.

HESS FD 2000. Light-dependent herbicides: an overview. Weed Science 48: 160-170.

INOUE MH et al. 2008. Lixiviação e degradação de diuron em dois solos de textura contrastante. Acta Scientiarum Agronomy 30: 631-638.

MADALÃO JC et al. 2012. Uso de leguminosas na fitorremediação de solo contaminado com sulfentrazone. Pesquisa Agropecuaria Tropical 42: 390-396.

MADALÃO JC et al. 2017. Action of Canavalia ensiformis in remediation of contaminated soil with sulfentrazone. Bragantia 76:292-299.

MOOSAVI SG \& SEGHATOLESLAMI MJ 2013. Phytoremediation: A Review. Advance in Agriculture and Biology 1: 511.

OHMES GA et al. 2000. Sulfentrazone dissipation in a Tennessee soil. Weed Technology 14: 100-105.

OLIVEIRA JR RS. 2001. Atividade residual de imazaquin e alachlor+atrazine para plantio sequencial de canola. Ciência Rural 31: 219-224.

OLIVEIRA JR RS et al. 2011. Sorption-desorption of aminocyclopyrachlor in selected brazilian soils. Journal of Agricultural and Food Chemistry 59: 4045-4050

PEREIRA FAR et al. 2000. Seletividade de sulfentrazone em cultivares de soja e efeitos residuais sobre culturas sucessivas em solos de cerrado. Revista Brasileira de Herbicidas 1: 219-224.

PIRES FR et al. 2005. Fitorremediação de solos contaminados com tebuthiuron utilizando-se espécies cultivadas para adubação verde. Planta Daninha 23:711-717.

PROCÓPIO SO et al. 2004. Seleção de plantas com potencial para fitorremediação de solos contaminados com o herbicida trifloxysulfuron sodium. Planta Daninha 22: 315-322.

RAUCH BJ et al. 2007. Dissipation of fomesafen in New York state soils and potential to cause carryover injury to sweet corn. Weed Technology 21: 206-212.

REIS MR et al. 2014. Aspectos fisiológicos e crescimento do girassol após aplicação de herbicidas em pré-emergência. Revista Agro@mbiente On-line 8:352-358.

RODRIGUES BN \& ALMEIDA FS 2011. Guia de herbicidas. 6.ed. Londrina. 697p.

SANTOS EA et al. 2007. Fitoestimulação por Stizolobium aterrimum como processo de remediação de solo contaminado com trifloxysulfuron-sodium. Planta Daninha 25: 259-265.

SILVA AA et al. 2007. Herbicidas: Classificação e mecanismo de ação. In: Silva AA \& Silva JF (Eds.). Tópicos em manejo de plantas daninhas. Viçosa: UFV. p.83-147.

SILVA LOC et al. 2012. Ação de Eleusine coracana na remediação de solos contaminados com picloram. Planta Daninha 30: 627-632.

SILVEIRA HM et al. 2012. Características fotossintéticas de cultivares de mandioca tratadas com fluazifop-p-butyl e fomesafen. Revista Agro@mbiente On-line 6: 222-227.

SZMIGIELSKI AM. et al. 2009. Development of a laboratory bioassay and effect of soil properties on sulfentrazone phytotoxicity in soil. Weed Technology 23: 486-491.

TAIZ L et al. 2017. Fisiologia e desenvolvimento vegetal. 6. ed. Porto Alegre: Artmed. 888p.

TORRES LG et al. 2012. Alterações nas características fisiológicas de cultivares de cana-de-açúcar submetida à aplicação de herbicidas. Planta Daninha 30: 581-587.

VARGAS L et al. 2014. Glyphosate influence on the physiological parameters of Conyza bonariensis biotypes. Planta Daninha 32: 151-159. 